\title{
High Rep Rate High Performance Plasma Focus as a Powerful Radiation Source
}

\author{
Sing Lee, Paul Lee, Guixin Zhang, Xianping Feng, Vladimir A. Gribkov, \\ Mahe Liu, Adrian Serban, Member, IEEE, and Terence K. S. Wong, Member, IEEE
}

\begin{abstract}
Basic operational characteristics of the plasma focus are considered from design perspectives to develop powerful radiation sources. Using these ideas we have developed two compact plasma focus (CPF) devices operating in neon with high performance and high repetition rate capacity for use as an intense soft X-ray (SXR) source for microelectronics lithography. The NX1 is a four-module system with a peak current of 320 $\mathrm{kA}$ when the capacitor bank $(7.8 \mu \mathrm{F} \times 4)$ is charged to $14 \mathrm{kV}$. It produces $100 \mathrm{~J}$ of SXR per shot $(4 \%$ wall plug efficiency) giving at $3 \mathrm{~Hz}, 300 \mathrm{~W}$ of average SXR power into $4 \pi$. The NX2 is also a four-module system. Each module uses a rail gap switching 12 capacitors each with a capacity of $0.6 \mu \mathrm{F}$. The NX2 operates with peak currents of $400 \mathrm{kA}$ at $11.5 \mathrm{kV}$ into watercooled electrodes at repetition rates up to $16 \mathrm{~Hz}$ to produce 300 W SXR in burst durations of several minutes. SXR lithographs are taken from both machines to demonstrate that sufficient SXR flux is generated for an exposure with only 300 shots. In addition, flash electron lithographs are also obtained requiring only ten shots per exposure. Such high performance compact machines may be improved to yield over $1 \mathrm{~kW}$ of SXR, enabling sufficient exposure throughput to be of interest to the wafer industry. In deuterium the neutron yield could be over $10^{10}$ neutrons per second over prolonged bursts of minutes.
\end{abstract}

Index Terms - Lithography, plasma focus, $\mathrm{X}$ ray.

\section{INTRODUCTION}

$\mathbf{F}$ OR MATHER'S type plasma focus operation it is observed experimentally [1], [2] that the quantity designated as the drive parameter [2] $S=(I / a) / \rho^{1 / 2}$ (where $I$ is the driving current, $a$ the anode radius and $\rho$ the operational gas density), a measure of speed, both axial and radial, has an optimum value for each gas of operation. Thus for deuterium the average axial speed for optimum neutron yield appears to be just below $6 \mathrm{~cm} / \mu$ s corresponding to a peak axial speed of $9-10 \mathrm{~cm} / \mu$ s and a peak radial speed of some 25 $\mathrm{cm} / \mu \mathrm{s}$ as the plasma focus radial shock goes on axis. That the optimum speed should be so low for optimum neutron yield is surprising since one would expect from D-D fusion cross section consideration that the fusion yield should be enhanced by an increase in speed which should boost the

Manuscript received July 19, 1997; revised March 19, 1998. This work was supported by research grants from Nanyang Technological University and the National Institute of Education under ARC5/94 and RP9/94LS, and IAEA Research Contract 7394/RB under a Coordinated Research Program.

S. Lee, P. Lee, G. Zhang, X. Feng, M. Liu, and A. Serban are with the School of Science, Nanyang Technological University, National Institute of Education, Singapore 259756 (e-mail: lees@nievax.nie.ac.sg).

V. A. Gribkov is with the P. N. Lebedev Physical Institute, Russian Academy of Sciences, Moscow, Russia.

T. K. S. Wong is with the School of Electrical and Electronic Engineering, Nanyang Technological University, Singapore 259756.

Publisher Item Identifier S 0093-3813(98)06365-6.

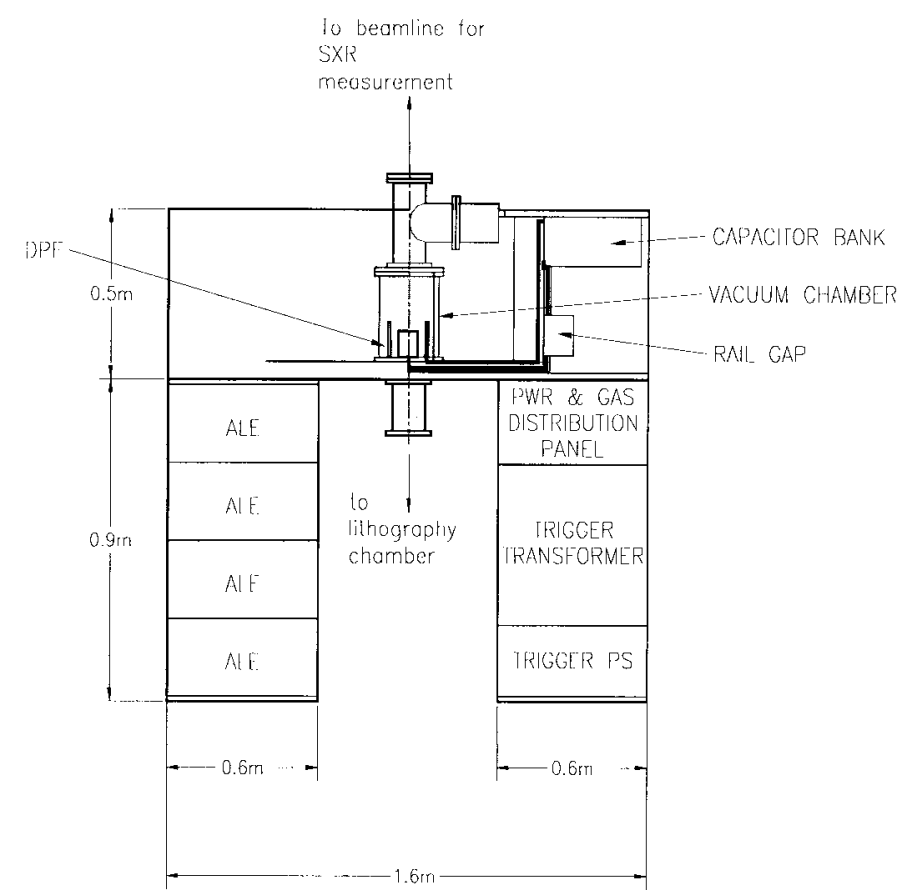

Fig. 1. General overview of the NX2 apparatus.

focus ions above the $1 \mathrm{keV}$ observed for focus operation at the above mentioned optimum speeds. The speed limitation may be caused by a force-field flow-field decoupling effect [1]. An effort to achieve yield enhancement by breaking through the speed limit has been made [3].

At this point it may be useful to remark that the drive parameter $S$ is a measure of the drive magnetic pressure per unit density or the drive magnetic energy per unit mass. Thus any model based on either the snowplow or slug model will have the driven speeds primarily dependent on this factor $S$. It may be necessary to apply correction factors to account, for example, for mass loss or current loss factors or even variations of such factors as the electromagnetic drive proceeds in stages. This applies to all electromagnetically driven plasma systems including the Z-pinch for which the implosion speed, treated either by a slug or snowplow model also scales as $S$ (see, for example, the discussion of implosion time scaling in reference [4]).

Operating in noble gases for the generation of soft X-ray (SXR) an optimum speed may be more readily understood. For example, in neon the compressed plasma in the focus should have a temperature of some $400 \mathrm{eV}$ if the radiation 
TABLE I

SuMmary OF EleCtricAl CHARACTERISTICS

\begin{tabular}{l|c|c|c|c|c}
\hline & $\begin{array}{l}\text { Charging } \\
\text { Voltage }(\mathrm{kV})\end{array}$ & $\begin{array}{l}\text { Energy } \\
(\mathrm{kJ})\end{array}$ & $\begin{array}{l}\text { Repetition } \\
\text { rate }(\mathrm{I} /)\end{array}$ & $\begin{array}{l}\text { Current } \\
(\mathrm{kA})\end{array}$ & $\begin{array}{l}\text { Short circuit rise time or } \\
\text { quarter period }(\mu \mathrm{s})\end{array}$ \\
\hline NX1 & 12 & 2.2 & 3 & 280 & 1.5 \\
\hline $\mathrm{NX} 2$ & 11.5 & 1.9 & 16 & 400 & 1.0 \\
\hline UNU/ICTP-PFF & 14 & 2.9 & Single shot & 170 & 2.2 \\
\hline
\end{tabular}

is required to be predominantly in the $0.8-1.4 \mathrm{~nm}$ for the purpose of microelectronics lithography. We have used a model computing plasma dynamics in the axial, radial, and radial reflected shock phases, incorporating a quasi-equilibrium radiative phase [5]-[7] to examine for example the optimum axial speed required to set the stage for optimum radiation in the $0.8-1.4 \mathrm{~nm}$ range. This model is used to correlate with experimental results which indicate an optimum average axial speed of $4.5 \mathrm{~cm} / \mu \mathrm{s}$.

It is important to note that the optimum speed for each of deuterium and neon operation remains nearly constant for the range of machines surveyed. This is particularly remarkable for deuterium operation where a value of $S$ nearly constant at $90 \mathrm{kA} /(\mathrm{cm} \text {-torr })^{1 / 2}$, corresponding to a peak axial speed of just less than $10 \mathrm{~cm} / \mu \mathrm{s}$, is tabulated [1] over a wide range of machines from training machines of $3 \mathrm{~kJ}$ [2] to machines of $300 \mathrm{~kJ}$. This means that for each gas the plasma temperatures in each of the dynamic phases, and by inference also in the compressed radiative phase, are identical for all machines, big and small, when optimized.

We next note that the quantity $S$ is dependent on $D=$ $(I / a)$ linearly whilst it depends only on the half power of $\rho$. Note also that over a two decade range of stored energy the optimized operational pressure has a range of only two [1]. Thus in a relative sense the density $\rho$ and hence the quantity $D$ may in the first approximation be considered also as constant when comparing different machines, all optimized. This clearly agrees with the design tendency to increase the anode radius proportionally with the available drive current. But there is also a fundamental significance.

For each gas, since we are dealing with the same compressed temperature and essentially the same density, radiation yield will depend on the product of compressed plasma volume and lifetime. Again since we are dealing with the same dynamical speeds and compressed temperatures any reasonable modeling [5], [8], [15] will show that each dimension of the pinched plasma is proportional to the anode radius, as is the lifetime of the compressed plasma. Thus radiation yield is proportional to $a^{4}$. And since $D$ is essentially constant for each gas, radiation yield, at least for neutrons and SXR, is proportional to $I^{4}$. Such a scaling is energetically possible since whenever energy is taken from the circuit by the plasma such an energy extraction will reflect in a lowering of the current. Such a self-regulating mechanism will self-consistently limit the extraction of energy from the circuit.

Thus for a given stored energy, yield performance is related to current. Circuit inductance needs to be minimized. Our modeling also indicates the importance of minimizing the ratio of generator impedance to total impedance for efficient transfer of energy to the plasma pinch. Practically, this is again accomplished by minimizing all the inductances from the capacitor bank through the switches right up to the collector flanges of the plasma focus head. Thus improving circuit performance should improve yield performance.

For applications, whilst the peak rates of yield may have significance for some time-resolved experiments, for other applications such as SXR lithography for microelectronics application there is a need for high average yield rates sustained over at least a duration of minutes, even for demonstration purposes. Thus ability to operate at high repetition rates in a prolonged burst is necessary.

The length of the anode is also of crucial importance [2], [8]. Computation and experience agree that a strong focus with optimum energy coupled into the focus pinch so as to emit intense radiation, is achieved when the radial compression starts (end of axial phase) at a time $t_{\mathrm{ax}}$ where $t_{\mathrm{ax}}$ is equal to $t_{r}, t_{r}$ being a hypothetical risetime of the capacitor bank with a value between the short-circuited risetime and the risetime of the circuit loaded hypothetically with the full axial load. As a rule of thumb the short-circuited risetime may be used for a first estimate of the optimum anode length.

Thus for the deuterium focus with an optimum average axial speed of say $5.5 \mathrm{~cm} / \mu$ s the anode length should be $5.5 \mathrm{~cm}$ per $\mu$ s short-circuited bank risetime. For the neon focus taking the optimum average axial speed to be $4.5 \mathrm{~cm} / \mu$ s would give us an indicative optimum anode length of $4.5 \mathrm{~cm}$ for every $\mu$ s of short-circuited bank risetime.

What about the value of $D=(I / a)$ ? From a survey of experiments it is found that the current per unit anode radius has a design range of $150-220 \mathrm{kA} / \mathrm{cm}$, for optimum neutron yield. We have used this range also as an indicative design range for our SXR facilities.

Based on the above considerations we have developed two high repetition rate compact plasma focus facilities, the NX1 and the NX2 ${ }^{1}$ to be powerful SXR sources for microelectronics lithography [9]-[11].

We note that the requirements for a point SXR lithography source may be expressed as follows: point source dimension less than $1 \mathrm{~mm}$ (focussed plasma viewed end-on) with emission in the wavelength range $0.8-1.4 \mathrm{~nm}$ and average SXR power of $1 \mathrm{~kW}$ at source over $4 \pi$ delivered over a prolonged burst. This last requirement indicates what is needed from industrial wafer throughout considerations. For a resist with $100 \mathrm{~mJ} / \mathrm{cm}^{2}$ sensitivity exposed at a distance which cannot be less than $30 \mathrm{~cm}$ [10] from the point source, 1

\footnotetext{
${ }^{1}$ The NX2 was manufactured and supplied by Alameda Applied Sciences Corporation, 2235 Polvorosa Avenue, San Leandro, CA 94577.
} 


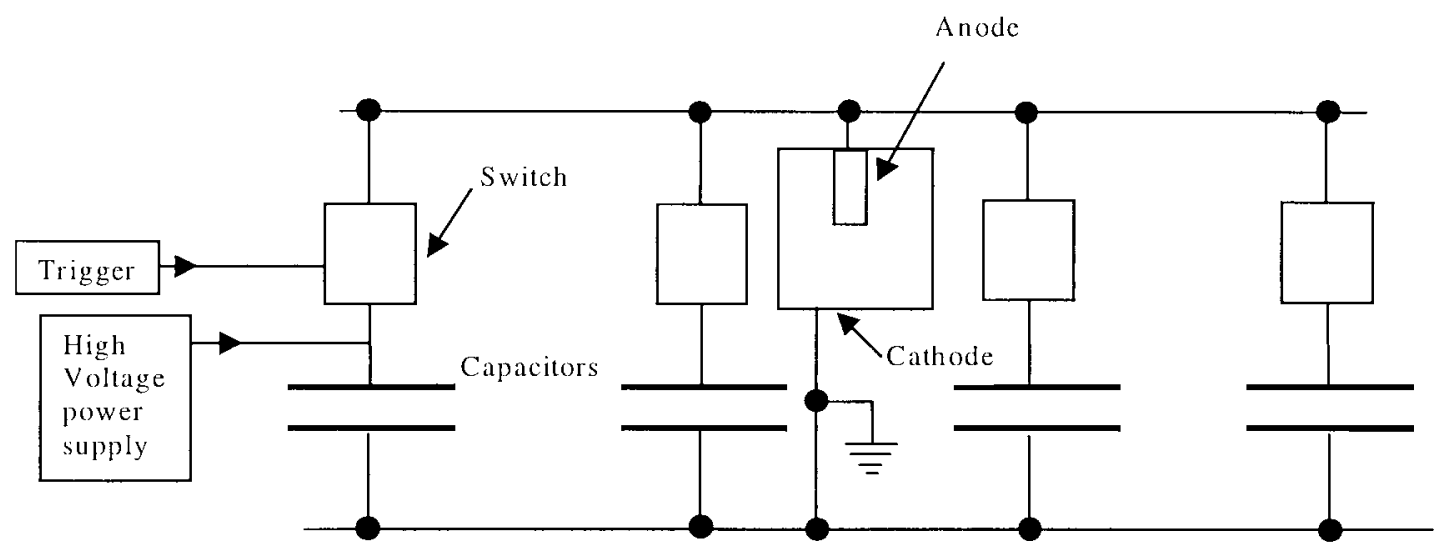

Fig. 2. Schematic of electrical system.

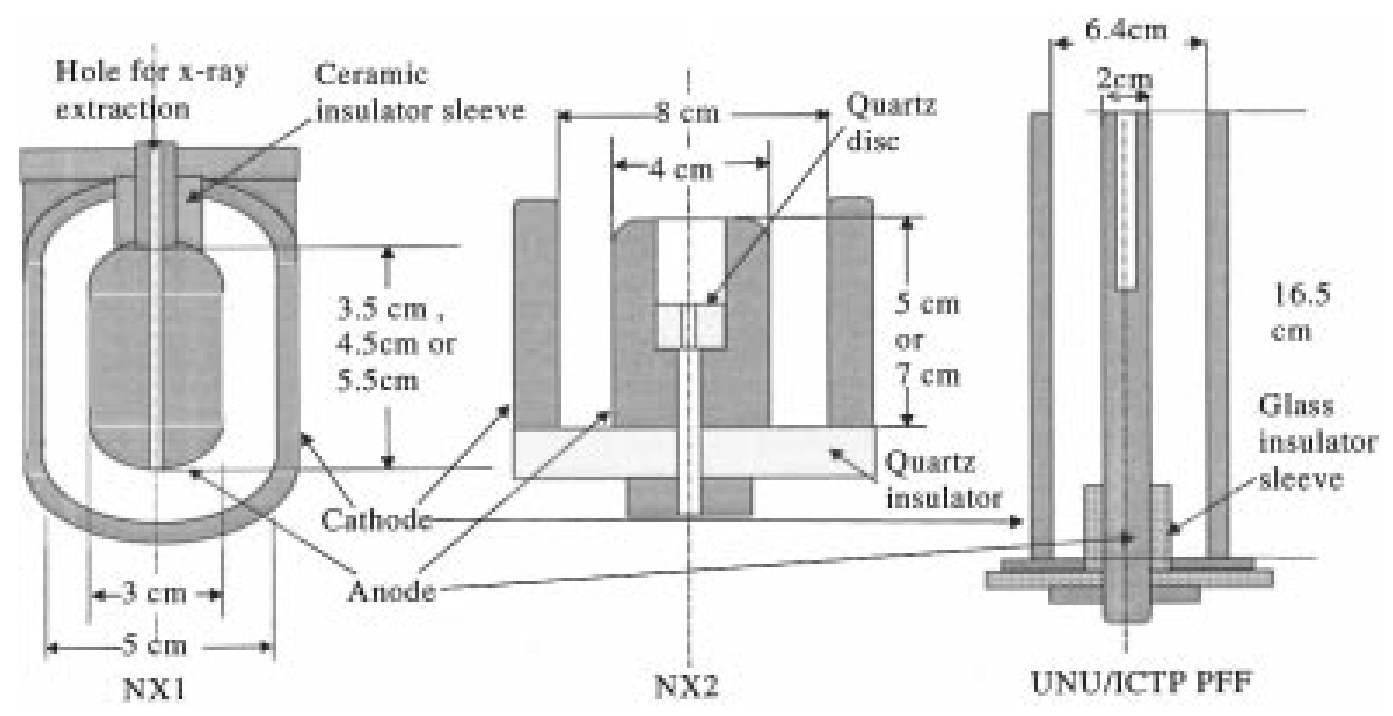

Fig. 3. Schematic of focus electrodes and chamber.

$\mathrm{kW}$ will deliver the required $100 \mathrm{~mJ} / \mathrm{cm}^{2}$ in $2 \mathrm{~s}$ assuming beamline transmission ratio of 0.5 . A $2 \mathrm{~s}$ exposure time per field may be sufficient for industrial wafer throughput purposes. For demonstration purposes even a $100 \mathrm{~W}$ source is useful.

Other practical design features include compact footprint with ample space for a stepper to be integrated eventually into the facility.

\section{APPARATUS}

The plasma focus soft X-ray sources used in these experiments are low energy $\sim 2 \mathrm{~kJ}$ plasma focus operated in neon. A general view of the NX2 is shown in Fig. 1. The design enables measurement of SXR yield at the same time as lithographic exposure is made. The footprint of the machine is $1.6 \mathrm{~m} \times 1.6 \mathrm{~m}$. There is a clear space for the integrated development of a stepper. The system is completely shielded against electromagnetic radiation.

Both the NX1 and NX2 plasma focuses are driven by $30 \mu \mathrm{F}$ capacitor bank charged by ALE Systems model 802 high volt- age capacitor chargers. The capacitor banks are connected to the focus via four switches (pseudo spark switches for the NXI and rail gap switches for the NX2). Table I summarizes the characteristics of the electrical systems of the NX1, NX2. The characteristics of a benchmark system the United Nations University/International Center of Theoretical Physics Plasma Focus Facility (UNU/ICTP PFF) [2] are also included in Table I. A schematic of the NX1 and NX2 electrical system is shown in Fig. 2. The UNU/ICTP PFF is a simpler system consisting of one capacitor coupled to the focus with one spark gap.

Three chambers have been used in the NX1 (see Fig. 3) with oxygen-free copper anode lengths $3.5,4.5$, and $5.5 \mathrm{~cm}$, respectively. Three anode lengths were tried with the NX2. The electrode dimensions are summarized in Table II. The NX2 stainless steel electrodes are cooled by water circulated through the electrodes using two Bay Voltex RRS-1650-AC chillers with a total cooling capacity of $9.6 \mathrm{~kW}$.

\section{EXPERIMENT}

The diagnostics were $1 \mathrm{~mm}^{2}$ area $10 \mu \mathrm{m}$ thick $p-i-n$ diodes and $3 \mathrm{~mm}^{2}$ photoconducting diamond (PCD) filtered by 
TABLE II

SUMMARY OF FOCUS ELECTRODES

\begin{tabular}{l|l|l|l|l|l|l}
\hline & $\begin{array}{l}\text { Anode } \\
\text { diameter }(\mathrm{cm})\end{array}$ & $\begin{array}{l}\text { Cathode } \\
\text { diameter(cm) }\end{array}$ & $\begin{array}{l}\text { Cathode } \\
\text { type }\end{array}$ & $\begin{array}{l}\text { Anode } \\
\text { length }(\mathrm{cm})\end{array}$ & $\begin{array}{l}\text { Electrode } \\
\text { material }\end{array}$ & $\begin{array}{l}\text { Insulator } \\
\text { matcrial }\end{array}$ \\
\hline NX1 & 3 & 5 & $\begin{array}{l}\text { Hollow } \\
\text { cylinder }\end{array}$ & $3.5,4.5,5.5$ & Copper & Ceramic \\
\hline NX2 & 4 & 8 & 16 rods & 5,7 & Stainless steel & Quartz \\
\hline UNU/ICTP PFF & 1.9 & 6.4 & 6 rods & 16.5 & Copper & Pyrex glass \\
\hline
\end{tabular}

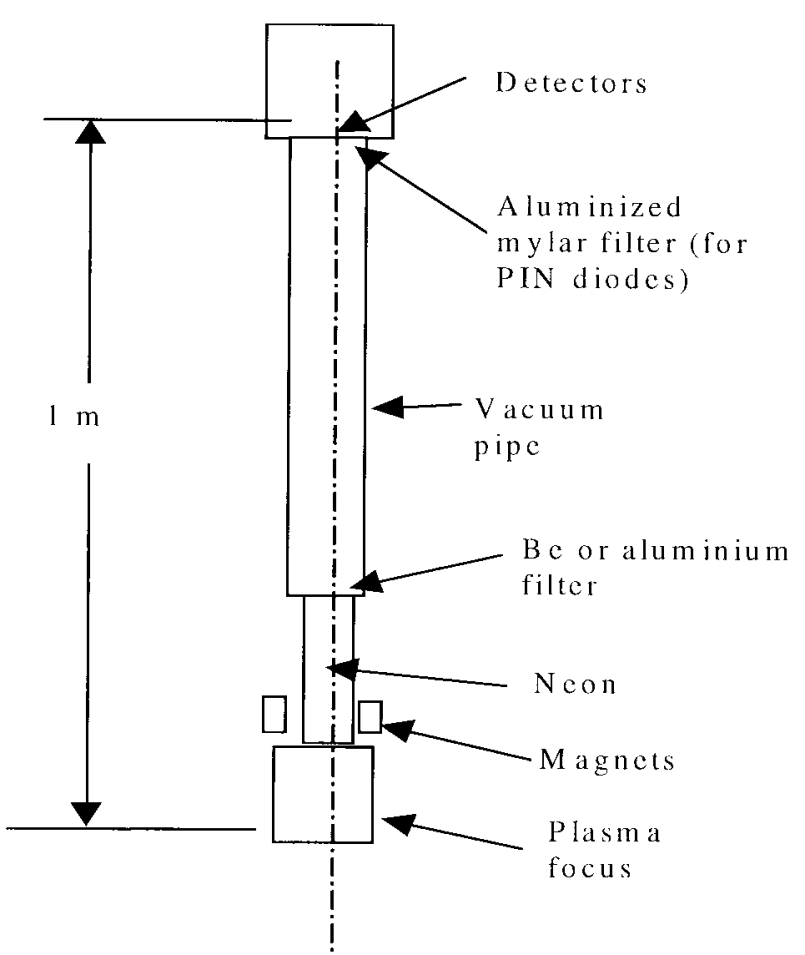

Fig. 4. Experimental set up for soft X-ray measurement.

aluminum, mylar, and beryllium foils. The setup used for the experiments is shown in Fig. 4. Both the PCD's and the $p-i-n$ diodes were used on both machines. In the case of the NX1, the X-ray was detected through the extraction hole through the anode. This means that there is also an electron beam traveling along the same path. The electrons are excluded by the application of a magnetic field to deflect the electrons and also by the $10 \mu \mathrm{m}$ beryllium which scatters the electrons. The energy of the electrons has been determined in a previous experiment [12] to be primarily less than $30 \mathrm{keV}$.

The initial pressure of neon was varied and the optimum pressure was found for the various electrode lengths and for charging voltages of $10 \mathrm{kV}$ and $14 \mathrm{kV}$. Most of the datapoints were repeated five to ten times for the NX1 and 20-200 times for the NX2. A fast acquisition system consisting of a tektronix TDS380 oscilloscope connected to a computer was used so that the X-ray for every shot up to a repetition rate of about 10 $\mathrm{HZ}$ could be obtained.

\section{RESULTS}

To obtain the SXR yield from the p-i-n diode pulse, the area under the oscilloscope trace is obtained and the total amount

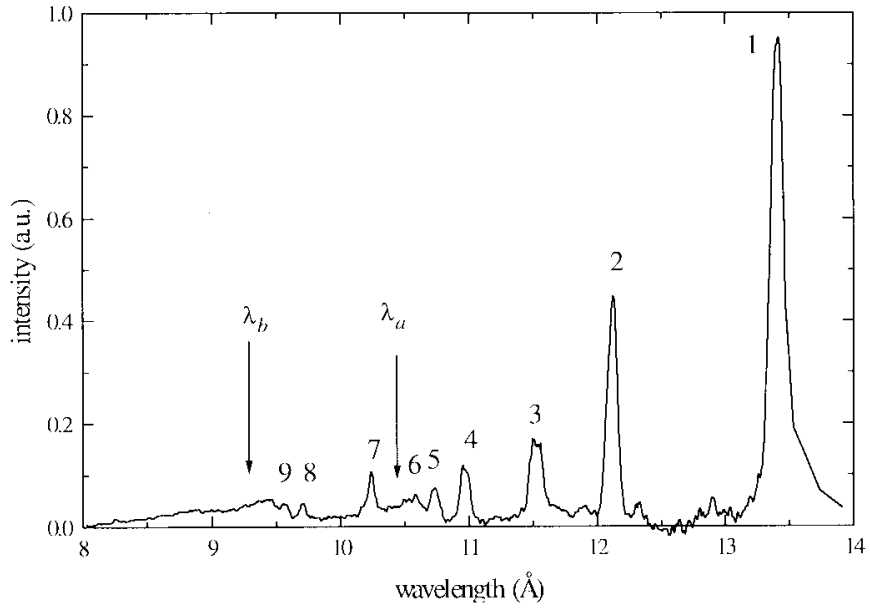

Fig. 5. Typical neon plasma focus spectrum.

of SXR is calculated using a sensitivity factor into which has been folded the sensitivity versus wavelength characteristics of the p-i-n diode, the spectrum of the neon focus emission (shown in Fig. 5) which had been separately obtained earlier using a crystal spectrograph [7], and the absorption of the beamline gas path and filters. The $p-i-n$ diode measurements are cross calibrated against a calibrated PCD detector. The PCD has a flat sensitivity over the range of SXR spectrum considered. Hence interpretation of the yield is more reliable. The measurements using the two detectors agree to within $20 \%$ on the NX2. All results are adjusted to the PCD calibration.

The results from the X-ray yield measurements are shown in Fig. 6. Fig. 6(a) shows that with the NX1, we obtained up to $5 \%$ conversion into soft X-ray from the capacitor bank energy and corresponding wall plug efficiency of $4 \%$ with the $4.5 \mathrm{~cm}$ anode at $12 \mathrm{kV}$. The X-ray yield varies within $50 \%$ of the maximum when the pressure is within $20 \%$ of the optimum. The typical variation of the X-ray yield, when other factors like neon pressure, charging voltage are kept constant, is about $\pm 35 \%$ of the average $\mathrm{X}$-ray yield.

Fig. 7 shows some representative oscilloscope current traces obtained using the NX1 with $4.5 \mathrm{~cm}$ anode operated with a charging voltage of $10 \mathrm{kV}$ and the NX2 with the $5 \mathrm{~cm}$ anode operated at $11.5 \mathrm{kV}$ with 4 mbar neon. Some currents dip to as low as $60 \%$ of the peak current when there is multiple focus within a short time of each other. More typical dips drop the current to $80 \%$ of the maximum, which is what the first dip associated with the first focus event in Fig. 6(a) shows. It can be seen that the energy transfer into the plasma is more efficient for the NX2 as the dip shown in Fig. 6(b) dips to about $65 \%$ of the peak current with only one focus event. In 


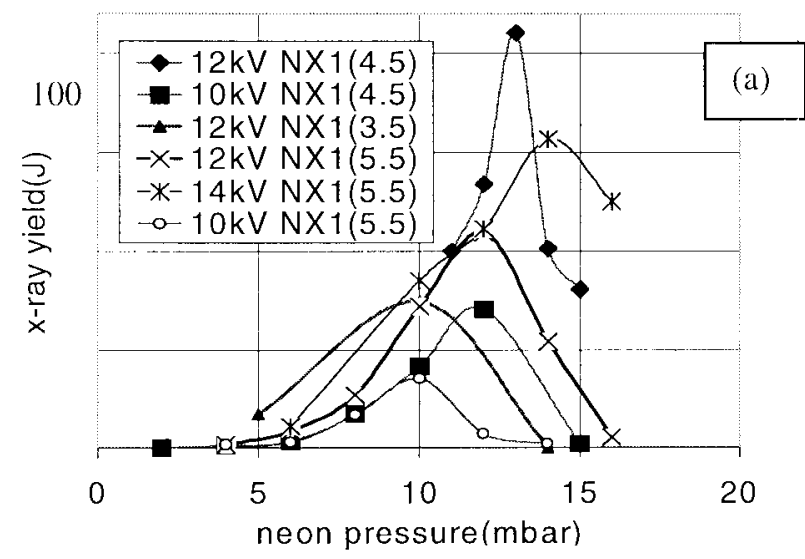

(a)

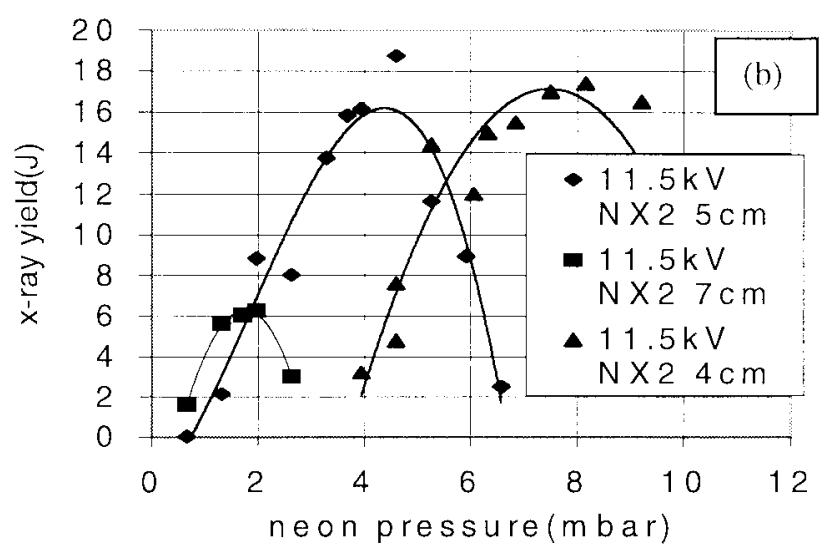

(b)

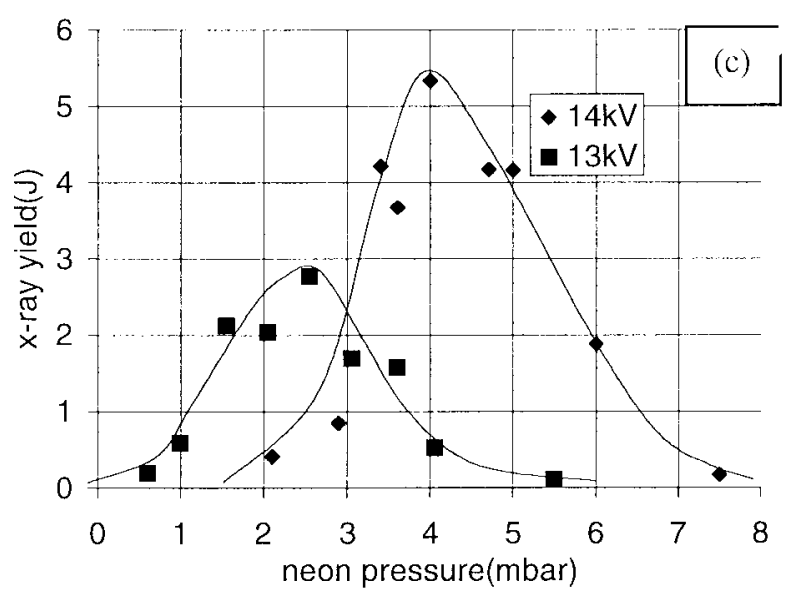

(c)

Fig. 6. X-ray yield for different neon pressures for (a) NX1, (b) NX2, and (c) UNU/ICTP PFF.

comparison, the UNU/ICTP PFF has a current dip of about $10 \%$ of the current maximum.

Table III shows the parameters for maximum X-ray yield for some of the configurations we tried. It can be seen that the best SXR yield is at an average velocity of $4.5 \mu \mathrm{scm}^{-1}$. With the shorter electrode, it is not possible to run the focus at a higher velocity as the focus would occur at a time too long before the natural current peak such that not enough of the capacitor bank energy has been converted to the magnetic

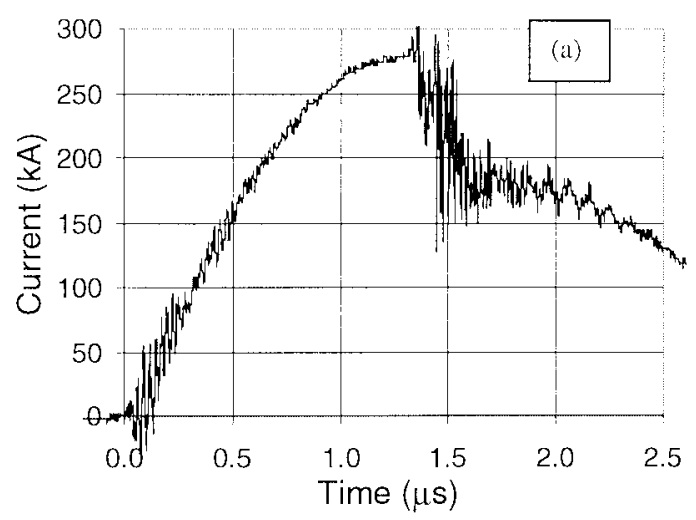

(a)

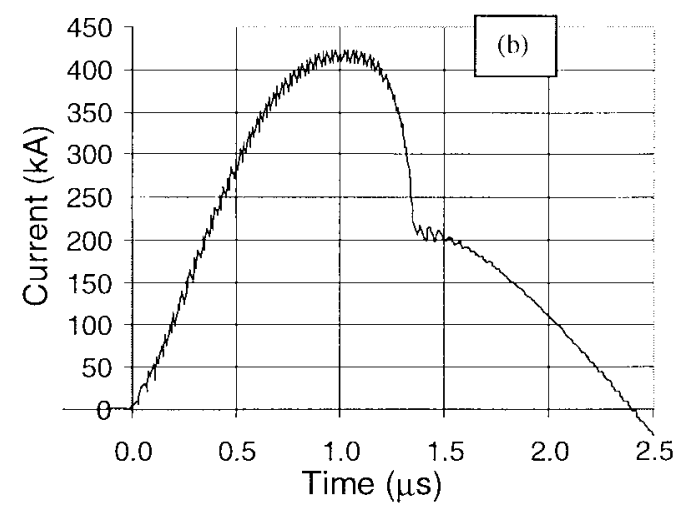

(b)

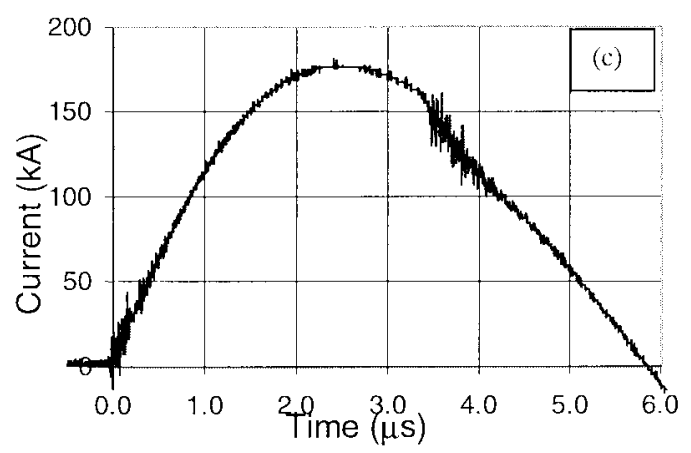

(c)

Fig. 7. Some representative oscilloscope traces obtained from (a) the NX1, (b) the NX2, and (c) UNU/ICTP PFF.

field energy driving the plasma. However if the anode is made too long and the velocity pushed too high, the final focus temperature will become too high for efficient production of neon $K$ shell lines.

Fig. 8 shows SXR lithographic exposures to confirm the SXR flux of NX1 and NX2 [13]. The resist used has a sensitivity rated at $100 \mathrm{~mJ} / \mathrm{cm}^{2}$ and is placed $40 \mathrm{~cm}$ from the focus. Magnets are placed to deflect the electron beams associated with the plasma focus [14] to ensure that the exposures are by SXR. The mask is a $1 \mu \mathrm{m}$ thick gold mesh with grid separation of $5 \mu \mathrm{m}$. The NX1 beamline has a three times poorer transmission ratio than the NX2 beamline. These lithographs confirm that the NX1 produces more than 
TABLE III

Comparative Performance of NX1, NX2, AND UNU/ICTP PFF

\begin{tabular}{|c|c|c|c|c|c|c|c|c|c|}
\hline Machine & $\begin{array}{l}\text { Bank } \\
\text { Voltagel } \\
\text { Energy } \\
(\mathrm{k} / \mathrm{kJ})\end{array}$ & $\begin{array}{l}\text { Length/ } \\
\text { Equival- } \\
\text { ent " } \\
(\mathrm{cm} / \mathrm{cm})\end{array}$ & $\begin{array}{l}\text { Opti- } \\
\text { mum } \\
\text { Pressure } \\
\text { (mbar) }\end{array}$ & $\begin{array}{l}\text { Mcas- } \\
\text { ured } \\
\text { Current } \\
\text { (kA) }\end{array}$ & $(\mu s)$ & $\begin{array}{l}\text { Average } \\
\text { Axial } \\
\text { Speed } \\
\left(\text { cmus }{ }^{-1}\right)\end{array}$ & $\left(\mathrm{kAcm}^{-1}\right)$ & $\begin{array}{l}\text { S } \\
(\mathrm{kA} \\
\mathrm{cm}^{-1} \\
\left.\operatorname{lorr}^{-1 / 2}\right)\end{array}$ & $\begin{array}{l}\text { SXR } \\
\text { yield } \\
\text { (I) }\end{array}$ \\
\hline NX1 & $10 / 1.5$ & $5.5 / 6$ & 10 & 230 & 1.50 & 4.0 & 153 & 56 & 20 \\
\hline NXI & $12 / 2.2$ & $5.5 / 6$ & 12 & 280 & 1.45 & 4.1 & 187 & 62 & 55 \\
\hline $\mathrm{NXI}$ & $14 / 2.9$ & $5.5 / 6$ & 14 & 320 & 1.40 & 4.3 & 213 & 66 & 80 \\
\hline $\mathrm{NXl}$ & $10 / 1.5$ & $4.5 / 5$ & 12 & 230 & 1.25 & 4.0 & 153 & 56 & 35 \\
\hline NX1 & $12 / 2.2$ & $4.5 / 5$ & 13 & 280 & 1.10 & 4.6 & 186 & 60 & 105 \\
\hline $\mathrm{NX1}$ & $12 / 2.2$ & $3.5 / 4$ & 10 & 280 & 1.10 & 3.6 & 187 & 68 & 35 \\
\hline $\mathrm{NX2}$ & $11.5 / 1.9$ & 7 & 2 & 340 & 1.30 & 5.4 & 170 & 139 & 7 \\
\hline $\mathrm{NX2}$ & $11.5 / 1.9$ & 5 & 4 & 400 & 1.15 & 4.4 & 200 & 115 & 18 \\
\hline $\mathrm{NX2}$ & $11.5 / 1.9$ & 4 & 7 & 410 & 1.05 & 3.8 & 205 & 90 & 15 \\
\hline UNU/ICTP-PFF & $14 / 2.9$ & 16.5 & 4.2 & 175 & 3.5 & 4.5 & 184 & 103 & 5.3 \\
\hline UNC/ICTP-PFF & $13 / 2.5$ & 16.5 & 2.8 & 165 & 3.5 & 4.5 & 174 & 119 & 3.5 \\
\hline
\end{tabular}

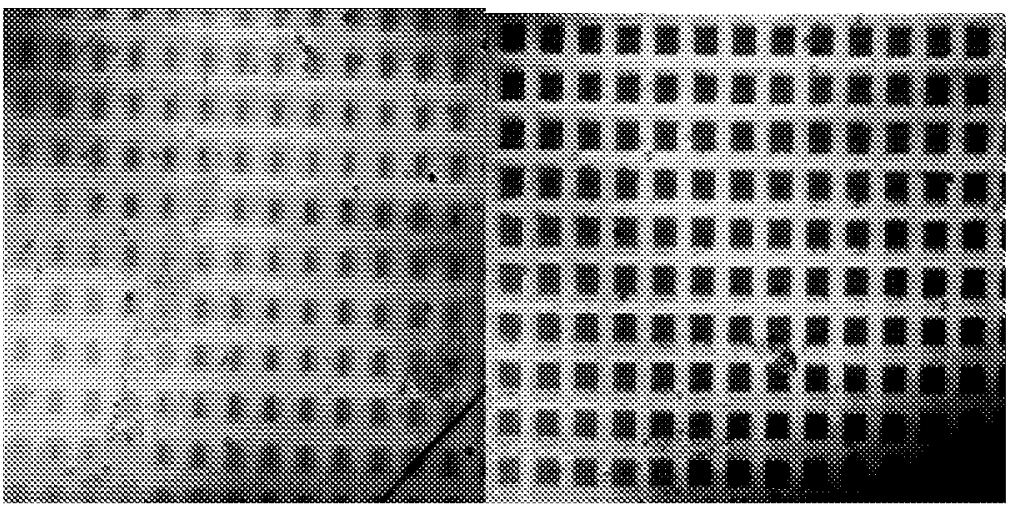

(a)

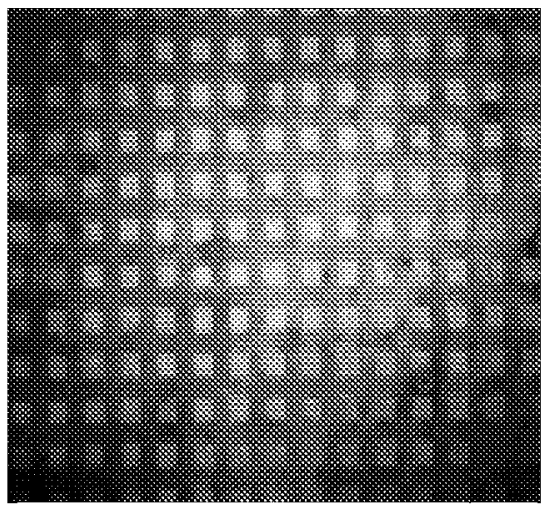

(b)

Fig. 8. Test exposure (a) NX1 (200 shots and 400 shots) and (b) NX2 (300 shots). Resist has arated sensitivity of $100 \mathrm{~mJ} / \mathrm{cm}^{2}$.

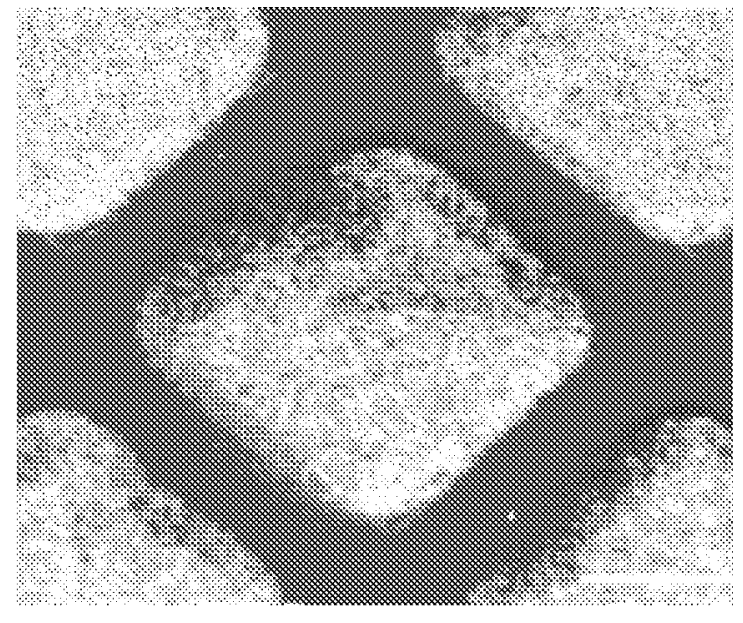

Fig. 9. Flash electron lithograph on PMMA, 10 shots (NX1).

three times the SXR yield per shot when compared to the NX2.

Fig. 9 shows a flash electron lithograph exposed on polymethylmethacrylate (PMMA) with ten shots of NX1. For electron lithographs the deflecting magnets were removed. The exposure was used to estimate the electron beam current as 50 $\mu \mathrm{A}$ over the $5 \mathrm{~Hz}$ burst. The electron energy was estimated as $30 \mathrm{keV}$ [13].

\section{CONCLUSION}

We note that the NX1 and the NX2 have quite different yield performances. For each machine the observed speed at optimum yield for each anode length generally does correlate with the drive parameter $S$. However the value of $S$ is significantly higher (up to two times) for equivalent speeds for the NX2 compared with the NX1. On the basis of machine scaling for neutrons [1] we would have expected constant value of $S$ for optimum operation. This difference may be the cause of the large difference in yield. Despite higher circuit performance the yield performance of the NX2 is significantly lower than the NX1. This may be due to the significantly lower value of $S$ for the NX1 which could be related to a higher operational density (up to three times) of NX1 for equivalent speeds and $D$, when compared to the NX2. The higher optimum operational density at equivalent temperatures obviously favors a higher SXR yield for NX1. This yield superiority of NX1 could perhaps be ascribed to differences in electrode materials (oxygen-free copper for NX1 compared to 
stainless steel for the NX2), chamber configurations (carefully shaped channel and closed outer electrode for the NX1), perhaps even to the differences in backwall insulation materials and configuration. In terms of $S$ values at optimum, the behavior of the UNU/ICTP PFF appears to be closer to the NX2 than the NX1.

In any case it appears that the NX1 chamber has the more promising features with maximum SXR yield over $100 \mathrm{~J}$ and wall plug efficiency of $4 \%$, compared to $18 \mathrm{~J}$ and $1 \%$ for the NX2. By incorporating cooling in the NX1 chamber and increasing the charging capacity so that the NX1 chamber may be fired at $10 \mathrm{~Hz}, 1 \mathrm{~kW}$ of SXR power may be achieved which will expose a field at $30 \mathrm{~cm}$ in less than $2 \mathrm{~s}$ on a $100 \mathrm{~mJ} / \mathrm{cm}^{2}$ resist, assuming a beamline transmission of 0.5 . This should be sufficient for industrial throughput demands applied to microelectronics lithography aimed at $0.15 \mu \mathrm{m}$ design rules.

Moreover, by using deuterium we expect a neutron yield of better than $10^{9}$ per shot and $10^{10}$ neutrons per second when operating the cooled NX1 in a prolonged burst at $10 \mathrm{~Hz}$. Such a powerful compact neutron source will have interesting applications.

\section{REFERENCES}

[1] S. Lee and A. Serban, "Dimensions and lifetime of the plasma focus pinch," IEEE Trans. Plasma Sci., vol. 24, pp. 1101-1105, June 1996.

[2] S. Lee, T. V. Tou, S. P. Moo, M. A. Eissa, A. V. Gholap, K. H. Kwek, S. Mulyodrone, A. J. Smith, Suryad, W. Usada, and M. Zakaullah, "A simple facility for the teaching of plasma dynamics and plasma nuclear fusion," Amer. J. Phys., vol. 56, no. 1, pp. 62-68, 1988.

[3] S. Lee and A. Serban, "Speed-enhanced neutron yield in plasma focus," in Proc. Int. Conf. Plasma Phys., vol, 1, Foz do Iguassu, Brazil, Oct. 1994, pp. 181-184.

[4] D. Mosher, N. Qi, and M. Krishnan, "A two-level model for $K$-shell radiation scaling of the imploding Z-pinch plasma radiation source," IEEE Trans. Plasma Sci., vol. 26, pp. 1052-1061, June 1998

[5] S. Lee, "A sequential plasma focus," IEEE Trans. Plasma Sci., vol. 19, pp. 912-919, Oct. 1991.

[6] S. Lee, "Factors limiting compressions-Applications to the radiative plasma focus," in Conf. Dig., Int. Conf. Plasma Sci. Technol. (ICPST'94), Chengdu, China, June 1994, p. 71.

[7] L. Mahe, "Soft X-rays from plasma focus," Ph.D. dissertation, Nanyang Technological University, Singapore, 1997.

[8] S. Lee, "Technology of a small plasma focus," in Small Plasma Experiments II, S. Lee and P. H. Sakanaka, Eds. Singapore: World Scientific, pp. 113-169, 1990.

[9] E. Cullmann, T. Kunneth, W. Neff, and K. H. Stephan, "Comparison of different X-ray sources using the same printing process parameters," $J$. Vac Sci. Technol, vol. 135, no. 3, pp. 638-640, 1987.

[10] R. R. Prasad, M. Krishnan, J. Mangano, and P. A. Greene, "Neon dense plasma focus point X-ray source for $<0.25 \mu \mathrm{m}$ lithography," SPIE, vol. 2194, pp. 120-128, 1994.

[11] Y. Kato and S. H. Be, "Generation of soft X-ray using a rare gashydrogen plasma focus and its applications to X-ray lithography," App. Phys. Lett., vol. 48, no. 11, pp. 686-688, 1986.

[12] P. Lee, X. Feng, G. X. Zhang, and S. Lee, "Electron lithography using a compact plasma focus," Plasma Sources, Sci., Technol., vol. 6, pp. 343-348, 1997.

[13] S. Lee, P. Lee, X. Feng, G. X. Zhang, M. H. Liu, A. Serban, S V. Springham, T. K. S. Wong, K. Wira, C. Selvam, and A. Thang, "Preliminary results on X-ray lithography using a compact plasma focus," SPIE, vol. 3183, pp. 123-127, June 1997

[14] J. R. Smith, C. M. Luo, M. J. Rhee, and R. F. Schneider, Phys. Fluids, vol. 28 , no. 7, pp. 2305-2307, 1985.

[15] S. Lee, "Energy balance and the radius of electromagnetically pinched plasma columns," Plasma Phys., vol. 25, no. 5, pp. 571-576, 1983.

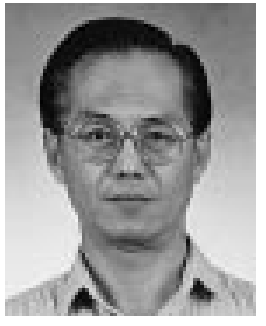

Sing Lee received the B.Sc. and M.Sc. degrees in physics in 1964 and 1966, respectively, from the University of Malaya (UM), Malaysia, and the Ph.D. degree in 1970 from the Australian National University, Canberra, Australia.

He was Professor of Applied Physics and headed research groups in plasma and pulse technology and the Physics Department at UM. He was an Alexander von Humboldt Research Fellow from 1975 to 1976 at Kernforschungsanlage, Juelich, West Germany, a Commonwealth Academic Staff Fellow from 1981 to 1982 at the Imperial College, London, U.K., and a Visiting Professor and United Nations Special Fellow from 1986 to 1987 at Flinders University of South Australia. He is the Founder and President of the Asian African Association for Plasma Training (AAAPT), the Associate Director of the AAAPT Research and Training Center at the Institute of Physics, the Academia Sinica, Beijing, China, and an Advocate and Implementor of SouthSouth technology creation and transfer, especially in plasma fusion, laser, and pulse technology. He is the Head of the Division of Physics, Nanyang Technological University, National Institute of Education in Singapore.

Dr. Lee is a Chartered Physicist, a Fellow of the Institute of Physics (U.K.), and a member of the Steering Committee of the International Center for Dense Magnetized Plasmas.

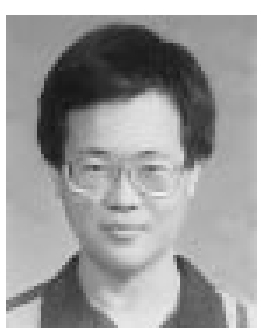

Paul Lee was born in Seremban, Malaysia, on November 10, 1970. He received the B.Sc. and $\mathrm{Ph} . \mathrm{D}$. degrees in physics in 1992 and 1996, respectively, from the University of London, Imperial College, U.K.

$\mathrm{He}$ worked as a Postdoctoral Fellow in the Microelectronics Division of the School of Electrical and Electronic Engineering, Nanyang Technological University, Singapore, from 1996 to 1997 . He is a Lecturer in the Division of Physics, School of Science, National Institute of Education, Nanyang Technological University. He has experience in the fields of pulsed power and laser technology, laser produced plasmas, Z-pinches, and plasma focus devices. His current research interest is soft X-ray sources.

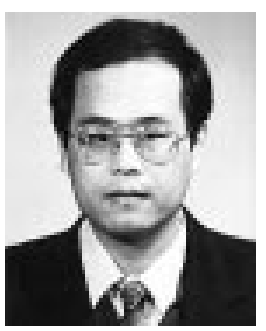

Guixin Zhang received the Bachelors and Masters degrees of Engineering from the Department of Electrical and Electronic Engineering, Tsinghua University, China, in 1987 and 1993, respectively. He is currently a Ph.D. student in Nanyang Technological University, Singapore.

He was an Electrical Engineer with China Structure and Construction Engineering Corporation from 1987 to 1988 . From 1988 to 1996 , he worked as a Lecturer and Deputy Head of the Gas Discharge and Plasma Laboratory at Tsinghua University. He has experience in the fields of high pulse power technology, high voltage engineering, plasma focus, gas puff Z-pinch, and holds two patents in fiber sensors. His current research is plasma soft X-ray sources for lithography.

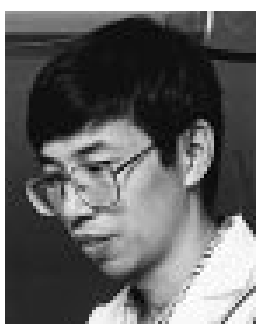

Xianping Feng received the B.S. degree from Jilin University, China, in 1982, the M.S. degree from Shanghai Institute of Optics and Fine Mechanics (SIOFM), China, in 1986, and the Ph.D. degree from Padova University, Italy, in 1993.

He was an Associate Professor at SIOFM, Head of the X-ray Spectroscopic Laboratory, China, and a Lecturer at the Nanyang Technological University, National Institute of Education, Singapore. He specializes in the area of X-uv and X-ray spectroscopy, laser plasma interaction, SXR's from the plasma focus and laser produced plasmas, and in SXR lithography. He has research experience and collaboration in several countries including Malaysia and Pakistan. 


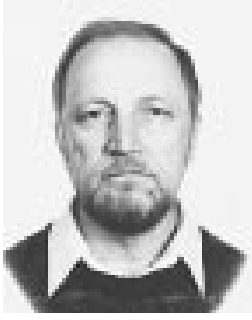

Vladimir A. Gribkov was born in Saratov, Russia, on June 30, 1944. He completed his public school education in Saratov, Russia, subsequently enrolled at the State University of Saratov, Russia, and later at the Moscow Physical Technical Institute, Russia, graduating in 1967. He earned the candidate and the doctor of the phys.-math. sci. degrees in plasma physics and chemistry in 1974 and 1990, respectively, from P. N. Lebedev Physical Institute, Russian Academy of Sciences, Moscow, Russia.

He joined P. N. Lebedev Physical Institute in 1967 with an appointment in the Department of Quantum Electronics. He is Professor of Physics-Mathematics Science of the Institute of Plasma Physics and Laser Microfusion, Warsaw, Poland and at the P. N. Lebedev Physical Institute, Russian Academy of Science Moscow, Russia. At present he is also a Co-Director of the Joint Plasma Focus Laboratory of the Institute of Plasma Physics and Laser Microfusion, Poland, and a Head of the Dense Plasma Physics Laboratory in the Neutron Physics Department of the P. N. Lebedev Physical Institute. He has been an Assistant Educational Professor since 1974 and full Professor since 1991 at the Moscow Engineering-Physics Institute. His professional activities of include research, teaching, consulting, and administration. His research interests have been concentrated in plasma physics, plasma diagnostics, pulsed laser, penetrating radiations facilities and its application to material sciences, X-ray lasers, and nuclear energy systems. He has published three monographs, several patents, and an excess of 130 papers in Russian and international scientific journals and has lectured at the Moscow Engineering-Physics Institute and conferences in Europe, the United States, and Canada. He also spent two months as an Invited Professor at the Buenos-Aires University, Argentina, and three months as an invited Professor at the Nanyang Technological University of Singapore.

Dr. Gribkov has been President of the Moscow Physical Society since 1994. $\mathrm{He}$ is a member of the Third World Plasma Research Network (TWPRN). He holds the State Award of the USSR Laureate for Laser Diagnostics of 1986 and the Polish Ministry of Science and Education Prize for Plasma Focus researches of 1987.

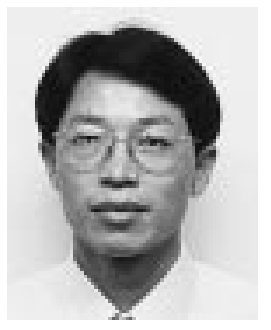

Mahe Liu received the B.Sc. degree from National University of Defense Technology, China, in 1985 the M.Sc. degree from University of Science and Technology of China, in 1990, and the Ph.D. degree from Nanyang Technological University, Singapore, in 1997.

He is currently a Post Doctoral Fellow at Nanyang Technological University. His research interests include pulse power technology, dense magnetized plasmas, X-ray measurements, and SXR source for lithography using plasma focus device.

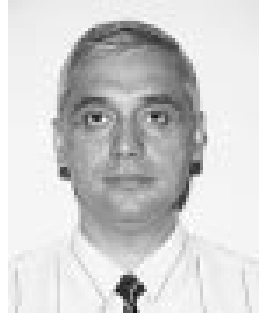

Adrian Serban (M'97) received the M.Sc. degree in physics from the University of Bucharest, Romania, in 1985, and the Ph.D. degree in physics from Nanyang Technological University, Singapore, in 1995.

He worked as a Physicist from 1985 to 1989 with the Research Institute for Computers, Bucharest. He then served as a Research Scientist from 1989 to 1992 with the Institute of Atomic Physics, Bucharest. He joined Nanyang Technological University in 1995 as a Postdoctoral Fellow and was appointed Lecturer with the Division of Physics of the School of Science in 1997. His research experience includes pulse power technology, dense magnetized plasmas, repetitive compact plasma focus devices as a soft X-ray source, liner implosions, ultrahigh magnetic fields, optical and spectroscopic diagnostic methods, thin film physics and technology, and recently, soft Xray microlithography.

Dr. Serban is a member of the Romanian Physics Society and the Institute of Physics, Singapore.

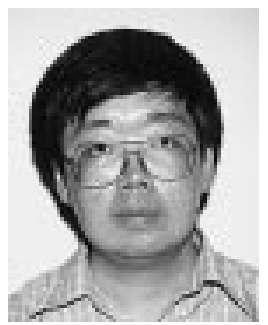

Terence K. S. Wong (S'83-M'92) received the B.A. degree (First Class) in electrical and information sciences and the Ph.D. degree in electrical engineering in 1987 and 1992, respectively, from the University of Cambridge, England.

From 1992 to 1994, he was a Lecturer at the Department of Electronic Engineering, The Chinese University of Hong Kong. Since 1994, he has been with the School of Electrical and Electronic Engineering, Nanyang Technological University, Singapore. His research interests include organic optoelectronic materials, microlithography, scanning probe microscopy, and semiconductor device fabrication.

Dr. Wong is a Chartered Physicist and a member of IOP and MRS. 